\title{
ELS CANVIS DE PARADIGMES CIENTÍFICS EN MEDICINA I LES DONES
}

\author{
ÀGUEDA GRAS-VELÁZQUEZ \\ ALBERT GRAS i MARTÍ \\ Universitat d'Alacant
}

\section{INTRODUCCIÓ}

Amb les revolucions profundes que ha patit la física en el segle XX s'ha produit un canvi de paradigmes científics que ha conduit a una reformulació de com analitzem el món físic, fet que està influint en altres camps del coneixement. De la mateixa manera que la física clàssica va contribuir a posar, fa segles, els fonaments per al desenvolupament d'altres ciències, com ara la química o la medicina, també la nova física està proporcionant noves perspectives a tots els camps de la ciència, des de la biologia fins a la sociologia.

En aquest treball farem una ullada a la medicina des de l'òptica dels paradigmes de la física, i adoptant-hi una perspectiva de gènere. Una àrea de recerca emergent és aquella que investiga les aportacions de l'anàlisi de gènere en les ciències (la biologia, les ciències fisicoquímiques, les enginyeries, etc.) ${ }^{1}$. En particular, l'anàlisi de la professió mèdica des del punt de vista de la categoria de gènere es veu facilitada per estudis semblants:

«L'estudi detallat de Moldow sobre les metgesses en el Washington de finals del segle XIX fa una contribució important [...] en establir, sense cap mena de dubte, que el gènere és una categoria crucial en les cultures professionals ${ }^{2} »$.

L'estudi esmentat mostra que les discriminacions i dificultats amb què es troben avui en dia les dones en la professió mèdica vénen de lluny, i que els petits avanços es produeixen, de vegades, per raons ben externes a la lluita fe-

1. SCHIEBINGER, L. (ed.): Gendered Innovations in Science and Engineering, Stanford, Stanford University Press, 2006.

2. ANTLER, J.: "Book review on Women Doctors in Gilded-Age Washington: Race, Gender and Professionalization, by Gloria Moldow», Journal of Social History, 22 (1989), p. 549. (Consultat el 30/4/07 en http://links.jstor.org/). 
minista $^{3}$. El camp de la salut i la medicina són molt amplis i s'hi han analitzat multitud d'aspectes, com ara la salut de les dones, les polítiques públiques, la medicalització de les dones ${ }^{4}$, o l'anàlisi de per què hi ha sectors feminitzats dins la salut, com és el cas de la infermeria. L'objectiu d'aquest treball és contribuir al debat sobre els canvis que s'estan produint en la pràctica mèdica i el paper de les dones en aquesta àrea, tant pel que fa als professionals com a les usuàries, des de la perspectiva dels vells i dels nous paradigmes de la ciència. Tot i les excepcions, és ben coneguda la poca visibilitat de les dones en el desenvolupament de la ciència:

«Segons mostren les biografies de les científiques, les dones han estat participant en la construcció de la ciència en totes les èpoques i en tots els llocs [...] una realitat llargament silenciada per la història de la ciència, en la qual les contribucions de les dones romanen, en general, invisibles" ${ }^{5}$.

En el passat, la dona es considerava una mera usuària o pacient dels avanços científics i mèdics. Però aportarem dades que indiquen que les dones estan en una bona posició per a contribuir als nous paradigmes mèdics i de salut que s'estan gestant. Les dones estan entrant en els àmbits tradicionals de la medicina, i especialment en els nous, amb molta més força que els homes, tant des del punt de vista de "clientes» o usuàries, com de terapeutes o metgesses. I aquest predomini femení es produeix, com veurem, no sols com a conseqüència de la tendència recent cap a la paritat de gènere que s'observa en molts camps professionals, sinó perquè els nous paradigmes de la medicina, més que no els vells, s'adapten millor a característiques, interessos i habilitats que tradicionalment s'associen a l'univers femení.

L'estructura del treball és la següent. Per centrar el tema comentarem en primer lloc quin ha estat, i en gran mesura és, el paradigma en què es basa bona part de l'anomenada medicina occidental o medicina «tradicional» i per què està en procés de canvi. Després veurem com les noves visions quàntiques del món estan influint en processos de canvi en l'àmbit de les medicines, i finalment analitzarem el paper de les dones en els vells i els nous paradigmes mèdics.

3. Com ara que algunes universitats dels EUA van obrir a les dones les portes de les facultats de medicina com una manera de generar més ingressos en una època de crisi, en les darreries del segle XIX. Però les van tancar de seguida, espantades per l'èxit d'entrada d'alumnat femení. Citat a ANTLER, J.: Op. cit.

4. Hi ha multitud de referències sobre el tema "Women in medicine and the medicalisation of women", que discuteixen si s'està convertint a tot el món en pacients, en especial a les dones. Una presentació interessant que resumeix el tema es troba a http://resources.bmj.com/files/talks/ santiago.ppt, i té el suggeridor títol de "Where are the limits of medicine: are we turning the whole world into patients?»

5. Miqueo, C.; Barral Morán, M.J.; Delgado Echevarría, I.; Fernández-Turrado, T.; MagaLLÓN, C.: "Del análisis crítico a la autoridad femenina en la ciencia», Feminismo/s, 1 (2003), p. 196. 


\section{VELLS I NOUS PARADIGMES}

Un paradigma és un «model d'investigació d'una disciplina científica dominant en un determinat període ${ }^{6}$ ». Ens referirem ací als paradigmes més importants que ha originat la física i que han impregnat totes les altres ciències, tant les fisicoquímiques i les enginyeries com les ciències socials i la medicina. En primer lloc comentarem el paradigma mecanicista, que va acompanyar l'origen de la ciència moderna. En l'apartat següent veurem com hem passat d'un univers mecànic a una interpretació quàntica de la realitat. Com ja s'ha analitzat en un altre àmbit en aquesta revista, cada paradigma té perspectives diferents d'observar:

"Malgrat com està d'arrelada la idea que els fets estan per ser percebuts, ja siga a simple vista, ja a través d'aparells diversos de mesura, açò no succeeix ni tan sols en les ciències que tracten de comprendre i explicar els fenòmens físics, ja que des de Hanson sabem que l'observació està carregada de teoria. Un raonament ja clàssic és partir de la noció kuhniana de paradigma. Un paradigma o model és una visió del món que conté elements bàsics de creença del que és la realitat i que constitueix un marc general que estructura la mirada, les observacions, permetent veure unes coses i no d'altres. Kuhn va posar de manifest que les aportacions veritablement revolucionàries en la ciència foren el resultat d'un canvi de paradigma, d'un canvi en les formes de veure la realitat. En situar-se en un nou paradigma, els científics van ser capaços de veure nous fets i noves relacions entre aquests, que tot i que hi eren no es feien visibles des de l'antic paradigma ${ }^{7}$ ».

\subsection{El paradigma mecanicista-reduccionista de la ciència}

La física newtoniana va introduir la idea d'un univers format per partícules que obeeixen unes lleis fixes, les quals determinen de manera absoluta el moviment de cada partícula. Amb aquest paradigma mecanicista es va introduir el concepte de determinisme: si es coneguera l'estat de l'univers en un instant qualsevol, se'n podria determinar l'estat en qualsevol instant posterior. Un s'imagina l'univers com un mecanisme de rellotgeria en què no hi caben les sorpreses. A més a més, el "reduccionisme» de la física, que tants èxits li ha aportat (el fet de descompondre un problema en les parts més petites possibles, i tractar d'explicar el comportament global a partir d'aquestes anàlisis parcials) es va adoptar com a eina bàsica del treball científic.

La influència de la física va abastar molts altres camps del saber. La formulació newtoniana de les lleis de la mecànica, i el desenvolupament posterior de la ciència, va fer possible la revolució industrial i tecnològica, i va conduir a una percepció mecanicista no sols de la naturalesa sinó també de la societat i de les persones. Per la seua simplicitat i per la potencialitat del mètode empíric, les

6. Diccionari de la llengua catalana, 2a edició, IEC, Edicions 62, Enciclopèdia catalana, Barcelona, 2007.

7. MAGallón PoRTOLÉs, Carmen: «Epistemología y violencia. Aproximación a una visión integral sobre la violencia hacia las mujeres», Feminismo/s, 6 (2005), p. 34. 
lleis de Newton es van convertir en un model a imitar per a filòsofs, pensadors socials, polítics i econòmics dels segles XVII al XIX. Per citar només tres exemples, el mecanicisme era l'exemple a seguir quan Adam Smith va modelitzar l'economia de lliure mercat i la divisió del treball, o quan Marx buscava les lleis deterministes de la història; i August Comte, inventor del terme «sociologia ${ }^{8}$ ", la va batejar primer com a "física social"». No és estrany, doncs, que també la medicina haja participat del mateix paradigma o visió del món. Aquest aspecte el desenvoluparem en la secció $3 a$.

Les metàfores sovint remarquen una determinada concepció de la realitat i encara avui dia es fan servir expressions relacionades amb el model mecanicista; es parla de les rodes del govern, de la maquinària de l'estat, es diu que som màquines pensants, que ens connectem i desconnectem, que es fonen els nostres fusibles, que estem "programats» per a l'èxit o el fracàs, etc.

El mecanicisme fa èmfasi en l'absolut, immutable i cert. L'ambigüitat n'és l'enemic. Les coordenades espai-temps de Newton són una armadura per a un univers fix, predictible, que obeeix lleis rígides. De la mateixa manera, en la societat mecanicista es fa èmfasi en el centre absolut i el poder s'irradia cap a fora; els rols són fixos i rígids. L'èmfasi és en la jerarquia. Des d'aquest punt de vista, doncs, el paper «transparent» de la dona durant segles, tant en la societat en general com en el món científic (i en particular en la medicina), es pot considerar una conseqüència natural de les lleis mecanicistes.

\subsection{Visió quàntica del món}

Els esquemes conceptuals de la física van patir al principi del segle XX dues grans revolucions: la teoria de la relativitat i la teoria quàntica, que van modificar la nostra comprensió de la realitat i de l'observación ${ }^{10}$. Els paradigmes de la física clàssica es van alterar profundament amb l'adveniment de la interpretació quàntica dels fenòmens de la naturalesa i, com veurem, aquesta nova perspectiva està començant a entrar en la teoria i en la pràctica mèdica.

La nova visió quàntica del món ha aportat conceptes i lleis totalment diferents de les de la visió clàssica mecanicista i, en particular, de com interactua la llum amb la matèria, i la ment amb la realitat material. Tot i que la física quàntica es va desenvolupar fa gairebé 100 anys, encara avui en dia moltes conseqüències de la interpretació quàntica dels fenòmens naturals s'estan començant a entendre i són motiu d'especulació. Per exemple, sorgeix com a possibilitat que hi ha més d'un univers i que estem constantment interactuant amb molts

8. KaPOOR, A. N.; GUPTA, V.P. i GUPTA, M.: «A Dictionary of Sociology», Frontiers of Knowledge, Vol. III, New Delhi, Radha Pub., 2007.

9. COMte, A.: The positive philosophy of Auguste Comte, (freely translated and condensed by Harriet Martineau, with an introduction by Frederic Harrison (Volume 1), Ithaca, New York, Cornell University Library, 1975), London, G. Bell and sons, 1896, p. 8.

10. Per al tema que ens ocupa, els principis de la relativitat einsteniana no són rellevants perquè s'apliquen principalment a fenòmens que involucren velocitats enormes, comparables amb la de la llum. 
d'aquests universos "ocults». En un univers dinàmic, i segons aquesta hipòtesi, l'única realitat és la consciència ${ }^{11}$. És a dir, que hi ha més d'una realitat objectiva, i ens podem moure d'una a una altra.

Com a exemples de noves perspectives esmentarem la coneguda paradoxa del gat de Schrödinger ${ }^{12}$ o el fet que, d'acord amb interpretacions que resulten de l'experiment d'Aspect dels anys vuitanta, segons la teoria quàntica les partícules de l'Univers es poden considerar connectades. En l'experiment esmentat, dues partícules molt distants responen a influències externes com si es tractara d'un sol sistema, tot i que una partícula no es pot comunicar amb l'altra ${ }^{13}$.

És tema de debat si aquests i altres fets de la realitat "quàntica» poden fer algun paper en el funcionament del cos, o de la ment, i se'n fan anàlisis també des de les medicines:

«El significat de l'experiment [d'Aspect] va més enllà d'aquest fenomen particular. Confirma la forma de pensar sobre l'univers que és habitual en física quàntica: la idea que la matèria no està localitzada en l'espai [...] I si la vida ha evolucionat de manera que fa servir la connectivitat que revelen els experiments d'Aspect? I si la consciència no es limita a una manifestació particular de matèria en l'espai i el temps, sinó que rau en aquells aspectes de la matèria que van més enllà de l'espai i el temps? No tenim encara les eines conceptuals per a investigar aquestes idees científicament, però la nova comprensió sobre la matèria ja està tenint una influència profunda en com ens pensem en relació amb l'Univers. Estem en comunió amb l'Univers com un tot, i no hi som uns mers residents temporals en un racó ${ }^{14}$ ».

Impulsat pels canvis epistemològics deguts a les noves teories quàntiques es va encetar, en la primera meitat del segle XX, un corrent de pensament amb una nova perspectiva no reduccionista ni determinista. Aquesta nova percepció es va dirigir a molts camps del coneixement i, en particular, a la biologia i d'aquí a la medicina.

El segle XXI és el de l'exploració científica de noves visions de l'Univers, de la societat i de l'individu; en particular, la investigació del problema ment-

11. Franks, M.R.: The Universe and Multiple Reality, New York, Iuniverse, 2003; i també: What is the Meaning of Reality?, consultat el 19/10/05 en http://www.manyuniverses.com/meaningofreality. htm

12. La paradoxa del gat de Schrödinger es refereix a la situació en què un gat es troba dins d'una caixa hermèticament tancada i que conté una ampolla amb un verí. Si l'ampolla es trenca el gat mor. La física quàntica descriu l'estat del gat tancat en la caixa mitjançant una "superposició» dels dos estats possibles, viu o mort, amb un $50 \%$ de probabilitat cadascun. Únicament quan una persona obri la caixa, la realitat «col-lapsa» en una de les dues possibilitats. Si per exemple, en obrir la caixa el gat apareix mort, aquesta realitat immediatament es retrotrau a l'instant en què es va trencar l'ampolla. És a dir, l'acte de l'observació ha determinat l'esdeveniment.

13. LAPIEDRA, Ramon: Els dèficits de la realitat i la creació del món, València, Universitat de València, 2004.

14. GeRBER, R.: Vibrational medicine, Subtle-energy therapies, 3rd ed., New York, Bear \& Co., 2001, p. 245 . 
consciència, de la medicina quàntica o energètica ${ }^{15}$, o la societat quàntica ${ }^{16}$ (en contraposició a la visió reduccionista i determinista de la societat tradicional). Es fan esforços per analitzar la importància que pot tenir la teoria quàntica en aquests $i$ en altres camps. Tanmateix, com històricament ocorre sempre que hi ha propostes radicalment diferents, s'alcen veus en contra de les extrapolacions d'expressions i fets de la física a altres camps del saber ${ }^{17}$.

\section{EL CAS DE LA MEDICINA}

Es pot analitzar l'evolució de la ciència mèdica des dels paradigmes de la física que acabem d'esmentar. Així, de les aproximacions mecanicistes i reduccionistes que dominen l'actuació mèdica, s'està evolucionant cap a una visió més integradora. Discutirem breument les dues òptiques i quins canvis es produeixen en la societat, en els quals el paper de les dones és fonamental.

\subsection{El paradigma de la medicina "tradicional»}

El paradigma de la medicina occidental, fins fa ben poc, ha estat el de la medicina al-lopàtica la qual beu, en part, dels postulats de la física clàssica. Els pensadors newtonians veuen l'Univers com un mecanisme ordenat, predictible i diví. El principi que subjau a una màquina és que la funció del conjunt es pot predir com la suma de les seues parts; és el reduccionisme que s'ha esmentat abans. Es poden trobar molts models mecànics (a l'estil de la física newtoniana) en la medicina actual. Per esmentar-ne només uns quants: el comportament fisiològic i psicològic depenen del maquinari estructural (hardware) del cos i del cervell; el cor es veu com una bomba mecànica que envia oxigen i sang rica en nutrients; hi ha màquines que reemplacen el cor malalt; el ronyó es configura com un mecanisme automàtic de filtració $i$ intercanvi de toxines $i$ hi ha màquines d'hemodiàlisi per a ronyons malalts.

La tecnologia biomèdica ofereix peces de recanvi, però no un coneixement profund de com revertir o prevenir moltes malalties. L'ésser humà es veu com una màquina complexa i s'han sofisticat molt els estudis dels mecanismes de rellotgeria biològics fins al nivell molecular. Els cirurgians, per exemple, són «biollanterners» especialitzats: saben aillar i eliminar components «malalts» $\mathrm{i}$ reconnectar el sistema per tal que funcione adequadament. La teràpia basada en drogues, tot i que té uns mecanismes d'actuació diferents dels del cirurgià, segueix sent newtoniana i pren el cos com un biomecanisme complex. En lloc de bisturís es fan servir drogues sintètiques que ataquen teixits del cos predeterminats, per reforçar-los o destruir-los, segons el cas. Però tot i els èxits que obtenen, determinats problemes es resisteixen a la física i a la medicina, especialment els de caràcter "global», com ara el cos humà, el clima, els fenòmens

15. Ibíd.

16. Zohar, D.; Marshall, I.: The Quantum Society: Mind, Physics and a New Social Vision, New York, William Morrow \& Co., 1993.

17. Vegeu, per exemple, SiLVER, B.L.: The ascent of science, New York, Solomon, 1998, p. 399. 
col·lectius, etc. I un percentatge gran de malalties no són tractables amb mitjans tecnològics com els esmentats.

\subsection{Crisi de models? ${ }^{18}$}

En els anys setanta el ritme constant de progrés mèdic a què ens havíem acostumat des del final de la II Guerra Mundial va començar a defallir. Les malalties infeccioses havien sucumbit en gran mesura als antibiòtics i a les vacunacions. Tot i així, una població que envellia es veia empaitada per «epidèmies modernes»: malalties coronàries del cor, càncer, malalties degeneratives cròniques -artritis, diabetis-, etc., contra les quals la medicina científica semblava relativament ineficaç. Noves drogues (com ara la talidomida) tenien més efectes secundaris que beneficis, i noves tècniques quirúrgiques (com ara els trasplantaments de cor) pareixia que condemnaven als pacients a morts ajornades tecnològicament.

En el pla social, el fenomen ve acompanyat de caigudes de murs i de polaritzacions. El col-lapse de polaritats polítiques antigues es va lligar amb el declivi de collectius que ens eren ben familiars (classes socials, sindicats, partits polítics, esglésies) i a l'esgotament de les ideologies. Es va produir una crisi àmplia d'autoritat en la societat. Als anys noranta van sorgir noves preocupacions sobre els perills socials i mediambientals de les forces econòmiques globalitzades. En una era d'horitzons rebaixats i d'expectatives reduïdes es va escampar un clima d'escepticisme sobre tota mena d'experts. La societat viu immersa en el consumisme, materialisme, banalització (TV...), hedonisme, manca d'objectius, nul esperit d'esforç, etc. D'aquesta crisi de confiança en les estructures tradicionals de la societat i en la ciència no es podia escapar la pràctica mèdica.

A finals dels setanta es va celebrar un simposi sobre la crisi de la medicina moderna amb el títol "Tot va millor però ens sentim pitjor», que va captar molt bé la paradoxa: tot i que, des de qualsevol criteri objectiu, com ara l'esperança de vida o la mortalitat infantil, les persones vivien més anys i amb més salut que en qualsevol període històric anterior, cada vegada més persones es queixaven als seus metges que es trobaven malament. Just quan la classe mèdica començava a perdre confiança a la vista de les epidèmies modernes, molta gent es queixava de símptomes físics de fatiga, malestar i dolor, per als quals sovint era impossible descobrir cap causa orgànica ${ }^{19}$.

En les dues dècades següents, durant els anys noranta, va continuar a passos de gegant la divergència entre la millora objectiva i el deteriorament subjectiu. Mentre es reduien els ritmes de mortalitat, s'escampava més i més l'ansietat sobre la salut: SIDA, vaques boges, mòbils i línies de tensió elevada, etc. Governs, autoritats mèdiques i mitjans de comunicació es van dedicar a promoure estils

18. Adaptat de FitzPatrick, M.: "Alternative Medicine: Should we swallow it?», en The surrender of scientific medicine, London, Debating Matters, IOI (Institute of Ideas), Hodder \& Stoughton, 2002, pp. 63-66.

19. Vegeu, per exemple: Tosal Herrero, Beatriz: «Síndromes en femenino. El discurso médico sobre la fibromialgia». En aquest volum. 
de vida saludables i a conscienciar la població sobre malalties. Aquest procés es va iniciar com a resposta a la SIDA de finals dels anys vuitanta, i va continuar amb les malalties del cor i amb diverses formes de càncer en els anys noranta. La preocupació pels temes de salut es va intensificar.

En un període d'inseguretat social i política en augment, que encoratjava un sentiment creixent de vulnerabilitat individual davant dels perills mediambientals, les ansietats populars es van refugiar en qüestions de salut. Els intents de promoure un estil de vida més saludable sovint tenien l'efecte de fer que les persones se sentiren malaltes i acudiren als metges amb expectatives enormes, però sovint en sortien desil-lusionades. En descriure els símptomes que els preocupaven intensament, però que resultaven inescrutables, es trobaven que els metges es comportaven de manera insensible i poc amigable. En rebien anàlisis inapropiades $\mathrm{i}$ tractaments ineficaços, que els deixaven frustrats o enfadats. Calia utilitzar, doncs, uns models socials diferents. L'acomodació de la societat a les medicines alternatives i complementàries $(\mathrm{MAC})^{20}$ és una indicació de la pèrdua de valor de la medicina occidental. Els nous paradigmes científics (visió quàntica) i la crisi de valors, en particular de la medicina, han desembocat en el sorgiment de les MAC.

\subsection{Nous paradigmes en medicina}

La nova física està proporcionant conceptes i eines analítiques a la medicina, de la mateixa manera que la física clàssica hi va contribuir. Aquestes aportacions són més visibles en el camp de les MAC, on és ben freqüent l'ús de termes com ara camps d'energia, holografies, freqüències, vibracions, energia-matèria, etc. Per exemple, es fa servir el principi hologràfic per a descriure camps bioenergètics associats amb l'estructura fisicoquímica del cos humà, i es parla de cos eteri i d'energies (o freqüències) subtils:

«Els metges [newtonians] conceptualitzen el cos com una enorme màquina, controlada pel cervell i el sistema nerviós perifèric. Però, som els humans «màquines sublims»? O som mecanismes biològics complexos que estan en interacció dinàmica $a m b$ una sèrie de camps energètics vitals que s'interpenetren? ${ }^{21}$.

La medicina vibracional parla també de teràpies basades en "energies subtils»:

«El nou punt de vista de la sanació que inclou una visió en evolució de la matèria com una expressió d'energia, basat en el paradigma d'Einstein, s'anomena medicina vibracional. Veu els éssers humans com xarxes de camps energètics complexos que interaccionen amb sistemes físics/cel-lulars. Les malalties són estats de desequilibri d'aquells sistemes energètics. La medicina vibracional utilitza formes especialitzades

20. Farem servir l'abreviatura MAC per designar les Medicines Alternatives $i$ Complementàries, tot $\mathrm{i}$ que sovint aquesta denominació és criticada per les persones que les practiquen perquè el terme "complementari» o "alternatiu» pot suggerir subordinació.

21. Gerber, R.: Op. cit., p. 269. 
d'energia per a afectar positivament el desequilibri, i restaurar l'ordre que regula la fisiologia cel.lular ${ }^{22}$ ».

Ens manquen eines conceptuals $\mathrm{i}$ instrumentals per tal de poder investigar científicament les noves propostes terapèutiques o les noves visions de l'ésser humà (en les seues múltiples vessants) i la seua relació amb l'entorn natural amb què interacciona. Hi ha qui despatxa els promotors i practicants de les MAC com a simples xarlatans, però tenim molts exemples de grans científics (fins i tot premis Nobel), que fan recerca en camps que la ciència considera poc ortodoxos:

«No és difícil trobar científics molt qualificats que qüestionen els paradigmes dominants en disciplines com la Física o la Medicina [...] La interacció ment-matèria i els fenòmens paranormals són altres dels temes preferits dels dissidents. Atès que aquestes són àrees que es presten al xarlatanisme i l'engany, cal tenir un prestigi a prova de bombes per dedicar-se a investigar en aquest terreny ${ }^{23}$ ».

Les persones (els "pacients») cada vegada s'interessen més pels tractaments no convencionals per a les seues dolences o condicions de salut. En particular, com hem vist a l'apartat anterior, moltes malalties cròniques no responen bé als tractaments convencionals, i es cerquen respostes en tractaments alternatius. El nou paradigma de la medicina beurà de la física moderna i també d'altres tradicions mèdiques. Moltes teràpies alternatives s'han fet servir durant centenars d'anys, i són la font primària d'atenció mèdica a més del $70 \%$ de la població mundial. Tanmateix, hi ha poca informació de qualitat sobre si aquelles teràpies funcionen o no, o si són segures. Pacients i metges es veuen bombardejats per declaracions abundants sobre els poders curatius de moltíssimes teràpies complementàries i per un nombre semblant de denegacions, que les qualifiquen de xarlatanisme. On és la veritat? Cal dur la llum de la comprensió científica a les medicines complementàries. Les reaccions contra les MAC de l'establishment recorden sovint el procés seguit per les dones per ser acceptades com a metgesses, economistes, etc.

En els anys vuitanta es va iniciar un moviment fort que promou una medicina basada en l'evidència ${ }^{24}$ (en les proves, en les demostracions) i que integra tres elements: els coneixements especialitzats del terapeuta, els desitjos del pacient $i$ la millor evidència disponible. Els canvis són ràpids. Fa una dècada (meitat dels noranta) era risible parlar d'una "aproximació a les MAC basada en l'evidència».

22. Ibíd., p. 270.

23. CAMPANARIO, J. M.: "Científicos que cuestionan los paradigmas dominantes: Algunas implicaciones para la enseñanza de las ciencias», Revista Electrónica de Enseñanza de las Ciencias, 3 (2004), pp. 1-30. (Consultat el 12/9/06 en http://www.saum.uvigo.es/reec/volumenes/volumen3/ Numero3/ART2_VOL3_N3.pdf).

24. El grup de recerca del prof. Ernst, catedràtic de Medicines Complementàries a la Universitat anglesa d'Exeter, revisa sistemàticament les publicacions científiques sobre les MAC. De cada teràpia complementària tracta de mostrar el seu origen, els conceptes subjacents, l'esquema racional en què s'hi basa, el mètode de pràctica clínica, a quines "condicions» o malalties s'aplica principalment i quines evidències (quines proves) hi ha sobre la seua seguretat i efectivitat. 
L'elit mèdica i científica ha canviat en pocs anys les percepcions sobre les MAC, en aquest ordre:

«- No funcionen i, per tant, no poden funcionar.

- Totes aquestes aproximacions són placebos.

- No totes són placebos, però algunes són perilloses.

- No totes són placebos i no totes són perilloses, però no es presten a un estudi rigorós científic sobre la seua eficiència o seguretat ${ }^{25}{ }^{\prime}$.

El darrer pas és conseqüència de la publicació d'estudis clínics ben dissenyats. En resum, doncs, estem en un moment en què no es pot destriar el gra de la palla:

«Hi ha insatisfacció davant el reduccionisme mèdic (especialització excessiva, terapèutica química dirigida a objectius massa parcials, corrupció pels interessos de les multinacionals farmacèutiques, etc.) $i$ tenen èxit popular les medicines alternatives que posen l'èmfasi en l'estudi del cos o de l'ésser humà com a totalitats (des de la medicina homeopàtica a tota mena de curanderismes que parlen d'energies, aliments màgics o força espiritual) $)^{26}$ ".

En un altre article d'aquest volum es tracta el problema de la indústria farmacèutica ${ }^{27}$. I encara més, sembla que reapareix l'eterna disputa sobre l'existència del vitalisme:

"Les teràpies energètiques es basen en l'antiga idea que la matèria viva té alguna força vital especial o energia que la fa diferent de la resta de la matèria. Avui dia aquesta energia s'associa equivocadament amb camps electromagnètics o quàntics. No s'ha trobat, però, cap evidència d'aquestes forces, energies o camps vitals ${ }^{28}$ ".

En el futur proper es donarà, molt probablement, la convergència dels dos móns, el de la medicina clàssica i les MAC. La pràctica mèdica ortodoxa està reaccionant $\mathrm{i}$ adopta actituds i mètodes de les MAC que, potser, li eren també propis en el passat.

La situació és complexa però apassionant. Durant molt de temps, com hem vist, les ciències han donat una visió mecanicista de l'Univers com a format per partícules en moviments determinats per forces externes. Ara sabem, però, que l'Univers és autoorganitzatiu i autocreatiu. En la nova imatge tot l'Univers es troba radicalment entrellaçat. Aquesta nova comprensió científica es basa en la

25. ERnst, E.; Pittler, M.H.; WIDER; B.: A desktop guide to Complementary and Alternative Medicine, An evidence-based approach, 2nd edition. Baltimore, Mosby Elsevier, 2006, p. IX.

26. TERRADAS, Jaume: Biografia del món. De l'origen de la vida al colllapse ecologic, Barcelona, Columna, 2006, p. 60.

27. Papí GÁlvez, Natalia; CAmbronero SaIz, Belén; Ruiz CANTERO, $M^{a}$ Teresa: «El género como "nicho»: el caso de la publicidad farmacéutica». En aquest volum.

28. Stenger, V.: "The Physics of Complementary and Alternative Medicine», treball en vies de publicació, consultat el 2/12/06 en http://www.colorado.edu/philosophy/vstenger/Medicine/ PhysCAM.pdf. També es pot veure la presentació «Energy: a physicist's view» a http://www. colorado.edu/philosophy/vstenger/Medicine 
teoria quàntica i en les teories del caos i de sistemes dinàmics, i en la teoria de la complexitat:

"Avui en dia la física ens diu que els processos irreversibles tenen una importància constructiva immensa: la vida no seria possible sense ells. La reversibilitat i el determinisme sols s'apliquen en casos límit, senzills, mentre que la irreversibilitat, les fluctuacions, i l'aleatorietat constitueixen la regla. Els sistemes físics, biològics i socials (com la natura, la vida, la humanitat, la ment i la societat) són invariablement dinàmics i evolutius. L'estudi de la complexitat representa una revolució important en la ciència actual, i constitueix una frontera inexplorada, una vegada el microcosmos i el macrocosmos han estat bastant explorats ${ }^{29}$ ".

En aquest moment històric la societat compta, afortunadament, amb una gran implicació de les dones en tots els àmbits d'activitat, que amb seguretat ajudaran a avançar en els problemes i a obtenir-ne noves perspectives. Per exemple, l'ús de la medicina complementària o alternativa és un moviment fortament promogut pels consumidors, és a dir, els (i sobretot, les) pacients la reclamen. I en aquest moviment, les dones tenen un paper essencial ja que, de sempre, han estat les mitjanceres entre el sistema de salut i els familiars malalts.

\section{EL PAPER DE LES DONES EN ELS VELLS I NOUS PARADIGMES MÈDICS}

Com hem vist a les seccions anteriors, les estructures i autoritats patriarcals que han dominat la medicina en el passat, i que encara sobreviuen en molts àmbits, fan que les dones -metgesses, pacients- tinguen dificultats en el món de la salut. Moltes publicacions s'adrecen a l'anàlisi de les qüestions de gènere de la professió mèdica i com la participació femenina pot aportar noves perspectives. Per exemple, Pringle ${ }^{30}$ troba que en àmbits que tradicionalment estaven altament masculinitzats en el passat, como ara el de cirurgians, la cirurgiana pot aportar més facilitat per a la col·laboració i menys interès en formalitats i en «mantenir les distàncies» amb els col-legues. Comenta l'autora, també, que les dones tenen dificultats en entrar en la professió mèdica, llevat que provinguen de famílies amb alts nivells culturals i econòmics. Malauradament, continuen els casos de discriminació cap a les dones en el món de la medicina, però gràcies a les TIC (Tecnologies de la Informació i la Comunicació) aquests fets es difonen ràpidament ${ }^{31}$.

29. SANChO, M.; Martínez, G.; Gras Martí, A.; Abril, I.: «Física y Biología: hacia una Ciencia de la Complejidad", Arbor: Ciencia, pensamiento y cultura (Ejemplar dedicado a: Biología y sus relaciones con otras ciencias), n ${ }^{\circ} 591$ (1995), pp. 99.

30. PRINGLE, R.: Sex and medicine: gender, power and authority in the medical profession, Cambridge, Cambridge University Press, CUP, 1998.

31. En Internet es poden trobar molts exemples, com ara: "Gender discrimination still an issue for women doctors.» Publicat en AMedNews.com. (Consultat el 2/10/07 en http://ama-assn.org/ amednews/2007/10/08/prca1008.htm). 
La ciència $i$, en particular, la medicina han estat fins fa poc pràctiques culturals governades per codis de conducta i per codis d'honor masculins ${ }^{32}$ i només de fa pocs anys ha començat a fer-se servir el "gènere» com una categoria d'anàlisi en aquest àmbit. Així, en la salut pública hi ha desigualtats de gènere que només es poden estudiar adequadament si tenim en compte els tres vessants, biològic, psicològic i social, com diu la Dra. Valls-Llobet:

«El biaix de gènere en medicina s'està manifestant de tres formes diferents: en primer lloc, partint de la suposició que els problemes i els riscs per a la salut de dones i homes són iguals, quan no ho són; en segon lloc, partint de la base que hi ha diferències biològiques i psicològiques on, finalment, només hi ha semblances; i en tercer lloc, partint de la suposició que els problemes de salut només són provocats per la discriminació cultural i social, sense altres interferències basades en les diferències biològiques ${ }^{33}$ \%.

Analitzarem tot seguit el paper de la dona en el món de la medicina, com a cas particular de les ciències, des de diversos punts de vista: com a estudiant, com a professional i com a persona malalta.

\subsection{Dones com a estudiantes}

Fa més de deu anys ja era evident la paritat de sexes en carreres com ara la biologia o la química, però no ho era així en d'altres com ara la física o les matemàtiques, o en les enginyeries, on els homes solen ser molt més nombrosos que les dones des dels primers cursos universitaris. Però conforme s'avança en els cursos de biologia o de química i, sobretot, en la carrera docent universitària, la paritat deixa d'existir. Per exemple, quan s'analitza la situació pel que fa al nombre de dones i homes en els diferents nivells de la carrera de biologia, es veu que mentre que en cursos de la carrera són $(\mathrm{D} / \mathrm{H})$ 147/142, i en graduar-se hi ha lleugerament més homes, (D/H) 101/118, en el nivell doctoral aquells dominen clarament, $(\mathrm{D} / \mathrm{H}) 27 / 57$, i són sis vegades més nombrosos els professors que les professores $(\mathrm{D} / \mathrm{H}) 7 / 42^{34}$. Es donen situacions ben semblants en la carrera de química. Per tant, tot i que la situació no és desigual en els nivells d'accés, sí que resulta ben desigual en els estudis de doctorat i entre el professorat universitari. Malauradament, aquesta situació no ha canviat gens en els darrers anys $s^{35}$.

Lawrence Summers, president de la Universitat de Harvard, va dir, tot i que es va retractar, que les dones no estudien ciència ni enginyeria perquè tenen

32. NYE, R.A.: "Medicine and Science as Masculine «Fields of Honor», Osiris, Women, Gender, and Science: New Directions, 12 (1997), pp. 60-79.

33. VAlls-Llobet, Carme: «Desigualtats de gènere en salut pública», La fábrica, 2006. (Consultat el 12-04-07 en http://www.fabrica.cat/index.php?option=com_content\&task=view\&id=126\& Itemid=31=. Vegeu, també, VAlls Llobet, Carme: Dones $i$ homes: salut i diferències, Columna, Barcelona, 1994.

34. "A study on the status of women faculty in science at MIT». (Consultat el 12/11/06 en http:// web.mit.edu/fnl/women/wmen.html).

35. En el treball de MIQUEO et al.: Op. cit., pp. 211-213, es donen algunes dades en la mateixa línia referides a l'Estat Espanyol. 
habilitats diferents dels homes ${ }^{36}$ : no va tenir en compte que potser a les joves se'ls fa pensar, des de ben petites, que no serveixen per a les ciències ni les matemàtiques. Però no hi ha diferències perceptibles avui en dia en el nombre de joves dels dos sexes a les aules universitàries de ciències. Les dones fan el 40$50 \%$ dels doctorats que s'acaben en biologia i són més de la meitat de l'alumnat que inicia una carrera de medicina. Però en física i en enginyeria les dones són menys del $20 \%$ dels doctorats. Un estudi de la Universitat de Michigan ${ }^{37}$ indica que les dones veuen les matemàtiques pures i la física com a professions aillades i no tan útils a la societat com la biologia o la medicina. Potser en alguns camps (física, matemàtica) no s'arribarà a la paritat de gènere, com en altres (biologia, medicina) però ens hi podem apropar si mostrem a les estudiantes que en aquelles carreres també es poden fer tasques per ajudar les persones ${ }^{38}$.

Molts estudis coincideixen en que les MAC són utilitzades principalment per gent jove, de sexe femení, amb estudis i de capes socials mitjanes o altes ${ }^{39}$. Enquestes fetes a estudiants de medicina d'ambdós sexes mostren que la gran majoria està a favor d'introduir més assignatures de formació en MAC durant la carrera ${ }^{40}$. Com que les dones són majoria en les aules de medicina avui en dia, aquest resultat es pot interpretar com una nova demostració de la major obertura de les dones als nous paradigmes. Tanmateix, calen estudis més detallats que tracten de contrastar aquesta hipòtesi.

En la pràctica mèdica tradicional també s'auguren canvis, com ja ocorre en alguns països on ja s'ha aconseguit la igualtat de gènere en les facultats de medicina $^{41} \mathrm{i}$ en molts pocs anys es llicenciaran més metgesses que metges. En un estudi fet entre estudiantes i estudiants de medicina es troba que les estudiantes:

«Tenen millor expedient acadèmic en la facultat de medicina i en els postgraus.

Tenen aspiracions majors.

Trien especialitats compaginables amb la família ${ }^{42}$ »

36. «Letter from President Summers on Women and Science». (Consultat el 12/11/06 en http:// www.president.harvard.edu/speeches/2005/womensci.html).

37. Niroomand-RAD, Azam: "Women Medical Physicists in AAPM. Report on Task Force On Women", CSWP Gazette 19 (2000), p. 6. (Consultat el 22/06/07 en http://www.aps.org/programs/ women/reports/gazette/upload/00f.pdf).

38. VANDERKAM, L.; DAVIDSON, J.: Genius denied: How to stop wasting our brightest young minds, New York, Simon \& Schuster, 2004.

39. ERnSt, E.: Op. cit.; PeRdiguero, Enrique; TOSAL, Beatriz: «Las medicinas alternativas y complementarias como recurso en los itinerarios terapéuticos de las mujeres. Importancia en nuestro contexto", en aquest volum.

40. CHEZ, R.A.; JONAS, W.B.; CRAWFORD, C.: «A survey of medical students' opinions about complementary and alternative medicine», American Journal of Obstetrics, 185 (2001), pp. 754-757.

41. REICHENBACH, L.; BROWN, H.: "Gender and academic medicine: impacts on the health workforce», British Medical Journal, 329 (2004), pp. 792-795.

42. Cooper, R.A.: "Medical Schools And Their Applicants: An Analysis», Health Affairs, 22 (2003), pp. 71-84 (Consultat 12/02/07 en http://content.healthaffairs.org/cgi/content/full/22/4/71). 


\subsection{Dones com a pacients}

Com ja s'ha comentat també en altres articles d'aquest volum és un fet cada vegada més evident que molts estudis científics sobre malalties comunes o sobre la resposta del cos humà a medicaments s'han fet només amb homes ${ }^{43}$. No estem parlant de malalties o condicions específiques d'algun sexe, com ara la malaltia de pròstata o el càncer de mama. En general, no es té en compte que poden haver -o no, però cal investigar-ho en cada cas- respostes diferents en els cossos de les dones, per les diferències de tot tipus que s'hi troben (hormonals, per exemple). En molts casos, com ara les malalties del cor, s'han trobat símptomes que pareix que són específics de cada gènere i això pot tenir conseqüències en els tractaments que se'ls hi donen. Es tracta de fer una "medicina de gènere», que compta ja amb revistes especialitzades ${ }^{44}$. La medicina occidental fa una mirada androcèntrica, esbiaixada, que pressuposa que els problemes d'homes i de dones són semblants i que és possible extrapolar-los:

«Molts assaigs clínics s'han fet només entre homes, suposant que els resultats es podien aplicar automàticament a les dones: estudi de fàrmacs antilipidèmics, efectes secundaris del tabac [...]. Dècades d'investigació en prevenció, mètodes de diagnòstic i programes d'intervenció han inclòs només homes com a subjectes de la investigació $\mathrm{i}$ els factors de risc $\mathrm{i}$ els protectors per a la salut detectats en homes s'han extrapolat directament a les dones. Per exemple, l'efecte de l'àcid acetilsalicílic contra els problemes cardiovasculars en l'home no s'han pogut demostrar en la dona. Per contra, factors de risc que són crucials per a la salut de les dones, com els causats per la sobrecàrrega desigual en l'atenció a la família i la feina domèstica, encara han de ser plenament investigats» ${ }^{45}$.

Es pot consultar la referència anterior per aprofundir en qüestions com la mirada andrògina en temes de salut i medicina, i la manca "d'una mirada de gènere no esbiaixada en l'atenció primària, en medicina interna i en les altres especialitats mèdiques, principalment la cardiologia ${ }^{46}$.

El reduccionisme, com s'ha esmentat en seccions anteriors, resulta limitant quan no es tenen en compte qüestions de gènere:

«Sembla que tant les circumstàncies socials com els processos biofisiològics contribueixen a les freqüències $i$ estadístiques observades. Una rígida adherència a una conclusió, excloent l'altra, és d'un provincianisme destructiu. A més, aquesta aproximació té com a resultat una incompleta i, a vegades, poc rigorosa explicació dels fenòmens. Aquesta rigidesa ha conduit a una investigació mal enfocada, a unes avaluacions inapropiades $\mathrm{i}$ a unes intervencions mal concebudes respecte a la malaltia. Com a resultat, el reduccionisme sociològic entre sociòlegs i treballadors de la salut

43. Perdiguero, E., Tosal, B.: Op. Cit.

44. Per exemple, el Journal of Women's Health \& Gender Based Medicine, http://www.liebertpub.com/ publication.aspx?pub_id $=42$

45. Valls-Llobet, C.: Op. cit..

46. Ibíd. 
pública s'ha convertit en tan destructivament miop com ho ha estat el reduccionisme biofisiològic entre els científics de ciències biològiques i naturals ${ }^{47}$ ».

Avanços recents en ciència i tecnologia han augmentat considerablement l'interès en diferències de sexe (biològiques, genètiques, fenotípiques) i de gènere (de comportament, socials) pel que fa a malalties i als resultats dels tractaments mèdics. Cada vegada hi ha més evidència que algunes malalties afecten de manera diferent homes i dones, i se n'estan investigant les causes. Però estem només en l'inici d'un llarg camít8.

Com a pacients, multitud d'estudis també mostren que les dones abracen més els nous paradigmes mèdics que els homes. Això és particularment cert en persones d'edat: s'han trobat clares diferències de gènere en l'ús de les MAC, ja què els homes les fan servir en menor proporció que les dones ${ }^{49}$. A banda, un fet demostrat àmpliament, i que respon als diferents trets psicològics, és que les dones són més obertes a parlar de MAC amb metges o metgesses, i de reconèixer-ne l'ús; les diferències de percentatge entre dones/homes solen superar el $10-20 \%$.

\subsection{Dones com a professionals}

La influència de la major quantitat de dones en professions que prèviament eren només masculines (com ara la cirurgia o l'anestesiologia) contribueix a que es produisquen canvis en la manera d'exercir la medicina: s'està passant d'un estil patriarcal, autoritari, a un estil més participatiu, menys competitiu, i amb més espai per a les emocions ${ }^{51}$.

No sols com a pacients, com ja hem vist, sinó també com a professionals, les dones abracen més els nous paradigmes mèdics que els homes: les metgesses, en major proporció que els metges, recomanen als seus pacients alguna forma de $\mathrm{MAC}^{52}$. A més a més, mentre els metges tendeixen a mostrar-se menys predisposats a l'ús de les MAC conforme n'augmenta l'edat, no es detecten diferències tan acusades entre metgesses joves i de més edat. Aquest fet es pot deure, en part, a la menor edat mitjana que tenen les metgesses en actiu en relació amb els metges en actiu. Encara hi ha ben pocs llocs web sobre les dones

47. MCKINLAY, J.B.: «Some contribution from the social system to gender inequalities in heart disease", Journal of Health and Social Behavour, 6 (1996), p. 22.

48. Correa-De-Araujo, R.: "Serious Gaps: How the Lack of Sex/Gender-Based Research Impairs Health", Journal of Women's Health, 15 (2006), pp. 1116-1122.

49. EisenberG, D.M.; Davis, R.B.; ETtNer, S.L.; Appel, S.; Wilkey, S.; VAn Rompay, M.; Kessler, R.C.: "Trends in alternative medicine use in the United States, 1990-1997: results of a follow-up national survey», Journal of the American Medical Association, 18 (1998), pp. 1569-1575.

50. NIH/National Center for Complementary and Alternative Medicine. "Older Americans Not Discussing Complementary And Alternative Medicine Use With Doctors». 2007. (Consultat el 12/10/06 en http://www.sciencedaily.com /releases/2007/01/070118121202.htm; informe en http://assets.aarp.org/rgcenter/health/cam_2007.pdf).

51. PRINGLE, R.: Op. cit.

52. ELDER, N.C.; GILlCRIST, A.; MinZ, R.: «Use of alternative health care by family practice patients", Archives of Family Medicine, 6 (1997), pp.181-184. 
i les $\mathrm{MAC}^{53}$ però de ben segur que aniran en augment, almenys proporcionalment, en relació amb els llocs sobre dones i medicina tradicional.

Una hipòtesi que es podria investigar és si les dones són les principals pacients i agents de les MAC perquè els fonaments i l'aplicació de moltes d'aquestes teràpies s'adapten millor a característiques de l'univers femení: saber escoltar, tenir paciència, capacitat d'observació i anàlisi de detalls, visió de conjunt, sensibilitat, empatia, capacitat de relació amb experiències pròpies viscudes, mirar el pacient, no sentir la pressió del temps, etc. Es pot donar una situació semblant a la que s'ha trobat, per exemple, en analitzar la capacitat de gestionar conflictes que poden tenir les dones i com es relaciona amb el tema de la cura i atenció de persones, una tasca feta tradicionalment per elles:

«Diferents investigacions [...] han demostrat que el rol de tenir cura d'algú implica el desenvolupament de determinades aptituds molt afins a la pau: la paciència, la tendresa, la responsabilitat, l'empatia, la perseverança, la prudència i la tolerància, entre d'altres, són components de l'acte de tenir curs d'algứ ${ }^{54}$ ».

I presentarem una altra àrea de recerca possible. Tot i que resulta difícil d'acotar quines teràpies inclouen les MAC, en moltes està present l'oració, la "curació espiritual» o el "toc terapèutic», com ara el Reiki. Potser ací hi ha una àrea fèrtil per investigar en termes de gènere, perquè les dones han sigut, tradicionalment, les més proclius al prec i a expressar-se mitjançant el contacte humà. L'atracció de les MAC es basa, principalment, en que anuncien «curacions» que fan servir productes "naturals», i els pacients se senten més informats; moltes se centren en aspectes com ara l'espiritualitat i l'estar bé emocionalment, i les persones que les practiquen tenen en compte les 3 t's del Dr. Strauss: tocar, temps i conversar (talk, en anglès) $)^{55}$.

Com s'ha dit a la secció 4.1., en alguns països s'ha aconseguit la igualtat de gènere en les facultats de medicina i aquesta "feminització de la medicina» ha donat com a resultat que cada vegada són més les metgesses: el 69\% a Rússia, actualment, i més de la meitat al Regne Unit, d'ací pocs anys ${ }^{56}$. En l'estudi esmentat també en l'apartat 4.1. s'ha vist que les metgesses tenen, estadísticament, comportaments diferenciats dels col-legues masculins:

- «Mentre que els metges es casen amb major probabilitat amb mestresses de casa i amb dones que no són professionals, les metgesses es casen amb més probabilitat amb altres metges.

- Prioritzen la família i els fills.

53. Rosenthal Center, Women's Health Information Resources, CAM resources (Consultat el 10/04/07 en http://www.rosenthal.hs.columbia.edu/Women.html).

54. COMINS MingOL, Irene: "La ética del cuidado: contribuciones a una transformación pacífica de los conflictos", Feminismo/s, 9 (2007), p. 105.

55. KaptChuK, Ted J.; EISENBeRG, David M.: "The Persuasive Appeal of Alternative Medicine», Annals of Internal Medicine, 129 (1998), pp. 1061-1065. Es pot veure, també, la presentació de Norma CUELLAR: "Culture and CAM», consultada el 12/02/07 en http://www.nursing.upenn. edu/centers/hcgne/PowerPoint/Cuellar-Culture_and_CAM.ppt

56. ReICHENBACH, L., BROWN, H.: Op. cit. 
- Treballen menys hores.

- Veuen menys pacients per hora que els homes.

- Abandonen la medicina en major proporció que els homes ${ }^{57}$ ".

Algunes persones poden veure aquesta actitud diferent cap al treball mèdic de dones i d'homes com un perill per a la professió i la pràctica mèdica, per les exigències de dedicació "a temps complet» que aquesta du associada tradicionalment ${ }^{58}$. Tanmateix, un altre punt de vista possible és que els nous paradigmes que s'estan desenvolupant en el mercat laboral (flexibilitat, mobilitat, menor dedicació horària, compaginació de tasques, més lleure, etc.) i que, en part, s'adeqüen més als desigs de les dones, poden acabar afectant i convenint tant a un sexe com a l'altre.

\section{CONCLUSIONS}

A la vista de les discussions de les seccions anteriors es pot concloure que els nous paradigmes mèdics i sobre salut afavoreixen la participació activa femenina, i que aquesta participació serà superior a la que s'esperaria de la tendència recent cap a la paritat de gènere que s'observa en molts camps professionals. De la mateixa manera que si les dones dissenyen un cotxe, aquest probablement tindrà un aspecte diferent del que és habitual ${ }^{59}$, s'està començant a sentir la influència de les dones en els camps de la ciència $i$, en particular, de la medicina. Les metgesses han fet avanços en temes de reproducció i estan promovent un concepte més ampli de salut femenina i, de rebot, de salut de les persones en general.

El camí per a les dones, però, no serà fàcil. Dins la professió mèdica, per a les dones es presenta un "dilema de la diferència» ja que es tracta d'aconseguir "com ser una dona i una metgessa, com ser diferent, i al mateix temps igual, que els col-legues masculins ${ }^{60}{ }$. Més precisament, aquest dilema s'ha centrat en tres aspectes que han hagut d'acarar les dones:

"Han lluitat per la igualtat professional en medicina, s'han resistit a la concepció unidimensional de la professió que tenien els metges masculins, i han intentat practicar una medicina "holística» mitjançant aspectes preventius, de salut pública i psicosocials de la medicina ${ }^{61}{ }_{\Perp}$.

La penetració de nous paradigmes en la societat sempre s'ha trobat amb obstacles. La Dra. M. Legato, de la Universitat de Columbia, explica, per exemple, que quan fa seminaris sobre com una medicina que siga específica per gènere pot canviar la pràctica mèdica, i es basa en molts resultats de recerca que de-

57. COOPER, R.A.: Op. cit., p. 80.

58. DOSANI, SABINA: «Implications of the gender revolution in medicine», British Medical Journal Career focus, 326 (2003), pp. 159-160.

59. Una visita a Google aporta moltes pàgines que tracten el tema de women design cars.

60. MORE, E.S.: Restoring the balance: Women physicians and the profession of medicine, 1850-1995, Cambridge, Harvard University Press, 1999.

61. Ibíd., p. 5. 
mostren que el cos femení i el masculí difereixen en aspectes fonamentals ${ }^{62}$, molts metges masculins abandonen bruscament el seminari perquè pensen que hi ha "una sola medicina per a tothom! ${ }^{63}$ ".

En la pràctica mèdica s'ha de tenir en compte la diferència entre igualtat de gènere i equitat de gènere ${ }^{64}$. La igualtat de gènere es refereix a que totes les persones tinguen igualtat d'oportunitats i accés als recursos; l'equitat de gènere, per altra banda, cerca la imparcialitat i la justícia pel que fa a oportunitats dins l'estructura professional. En aquesta línia, un aspecte poc estudiat encara és com fer que l'ensenyament i l'entrenament de futurs professionals tinga més en compte aspectes de gènere, de manera que els prepare per afrontar els problemes de salut de grups diversos. Això pot tenir conseqüències positives per als dos sexes:

«Si es preparen els metges per tractar adequadament les necessitats de salut de les dones es pot augmentar la demanda dels seus serveis, i fer que tinguen [els propis metges] major satisfacció laboral. Per altra banda, [aquesta formació en qüestions de gènere] també pot obrir als homes especialitats mèdiques que sovint s'associen amb metgesses, com ara la pediatria ${ }^{65}$.

La realitat social, però, inclou encara més complexitats. Avui en dia, els estudis de recerca mèdica de camp que es vulguen fer bé han de tenir en compte l'equilibri de gènere en la població a què se sotmet la prova $i$ també la diversitat ètnica de la mostra. I és que en moltes societats, inclosa la societat europea actual, la diversitat ètnica ha augmentat considerablement de fa pocs anys. En tot cas, hi ha molta tasca per fer i s'ha d'enfocar bé. Com conclou la Dra. VallsLlobet:

«La política neoliberal ha augmentat els problemes de la salut de les dones perquè ha fet més invisible la ideologia i ha canviat la orientació amb una visió més pobre sobre les diferències. Les dones s'han convertit en víctimes dels centres mèdics privats, i les seves veus i queixes s'han silenciat, així com les veus de les persones que estan investigant i formant sobre diferències de gènere. Crec que la salut pública ha de ser orientada cap al gènere $i$ contribuir a fer visibles les diferències reals perquè es puguin desenvolupar els processos de prevenció apropiats ${ }^{66} \%$.

62. Per exemple, que el cervell femení té més connexions intercel-lulars, i aquesta pot ser la causa que explique que les dones recuperen la parla després d'un infart molt més ràpidament que els homes; o que el cervell masculí té més serotonina, i això pot explicar per què els homes pateixen menys depressions. (Consultat el 14/03/06 en ABC News: How gender-specific medicine could change health care, en http://abcnews.go.com/WNT/story?id=301044).

63. Ibíd.

64. Reichenbach, L.; Brown, H.: Op. cit.

65. Ibíd., p. 794.

66. VAlLs-Llobet, C.: Op. cit. 